\title{
An Analytical Study of National and International Care Label Systems of Textile and Apparel Products
}

\author{
Reham A. Sanad ${ }^{\dagger 1)}$ and $\mathrm{Zi}$ Young Kang \\ ${ }^{1)}$ Dept. of Textile Printing, Dyeing \& Finishing, University of Damietta; Damietta, Egypt \\ Dept. of Fashion \& Textiles, University of Huddersfield; Huddersfield, UK
}

\begin{abstract}
This paper enables stakeholders involved in textile industry to gain an overview of standards used for care labelling and help establish a common standard that could be used as a universal standard. This study provides a comprehensive and detailed analytical study of care labelling standards adopted by common countries in the textile market. It was found that the development of a universal system for care labeling could enhance the trade of textile articles and assist consumers in caring for textile articles. Universal care label systems could be characterized by two main features of inclusiveness and comprehensiveness. The range of instructions and symbols presented were found different among standards. Insignificant differences in symbols' shapes were found between standards for bleaching, ironing and professional cleaning. The washing process had the widest variety of instructions; in addition, options were provided by stated standards. Different meanings were found for similar shapes in some tumble drying symbols. The study findings show the importance of enhancing text based standards or the development of an understandable format across as many cultures as possible. The unification of symbols and meanings may be needed to provide global consumers consistent guidance. The efficiency of a detailed standard that provides and covers a wide range of instructions is an important aspect. The visibility and practicality of offering variable options/symbols in one standard is an important aspect for developing a universal care label system.
\end{abstract}

Key words: agitation, bleaching, symbol, tumble, temperature, washing

\section{Introduction}

Labeling of textile articles is a method used for communication between consumer, manufacturer and trader regarding textile product information (Davis, 1987). Textile articles are yarns, piece goods and made-up articles such as apparel, household textiles, furnishings, upholstery, upholstered furniture or bedding containing at least $80 \%$ by mass textile material (British Standards Institution, 2012; Standards Australia \& Standards New Zealand, 1998). A textile article label aims at giving information related to the product such as fiber content, country of origin and size. A care label is the kind of labelling instructing the consumer to the ideal conditions of caring the purchased item (mainly laundry process) (Davis, 1987; Shin, 2000). It would consist of symbols and/or words (phrases) (ASTM International, 2001).

Several research studies have been carried out investigating the

$\dagger$ Corresponding author; Reham A. Sanad

Tel. +96-89-415-5860, Fax. +96-82-451-1193

E-mail: rehamsanad@du.edu.eg

(C) 2018 (by) the authors. This article is an open access article distributed under the terms and conditions of the Creative Commons Attribution license (http://creativecommons.org/licenses/by/3.0/), which permits unrestricted use, distribution, and reproduction in any medium, provided the original work is properly cited. importance of care labeling of textile articles. For consumers, care label assists taking purchase decision and appropriately caring for the purchased item (Shin, 2000). From the perspective of producers, providing appropriate and sufficient care instructions can improve consumer satisfaction giving a trustworthy impression as well as certainty in the liabilities derived from mistreatments or problems related to the merchandises. Besides, the application of care labels is an effective means for the manufacturers which lead to a reduction of extra costs compared to employing written instruction (Ruoh-Nan et al., 2008).

Research studies concerned with care labelling systems are almost focused on the comprehension of care labelling systems (Calisir et al., 2013; Ruoh-Nan et al., 2008; Shin, 2000), appropriateness of care instructions based on fiber content and consumers' perception (Choo \& Song, 2000), the influence of care instructions on consumers' estimation of clothing attributes (Workman \& Johnson, 1991), frequency of checking care labels, perception of textile labels in relation to environment and ethics (Kirsi \& Grimstad, 2013) and the history of the emergence of care symbols and regulations (Draxlerová et al., 2015).

Since the late 1950s, various national and international care label systems have been introduced, distributed and regulated in most countries to guarantee public credibility (Draxlerová et al., 2015; 
Shin, 2000) (Shin, 2000). Nowadays, these standards existing across the globe are of similarities and differences which would cause kind of difficulty and misperception among consumers, manufactures and traders. Furthermore, global standards have become increasingly an essential aspect of globalization improving the efficiency of world economy. Its importance lies in the need for common standards in order to smoothen and enhance international trade relations, improve competitiveness between companies and promote efficient markets. Moreover, there has been vital need for a harmonized standard due to complex relationship between all parties concerned with textile articles across the world i.e. manufacturers, suppliers, traders and consumers. It is noteworthy to find national standards are on the way of erosion due to growing positive impact of international standards. All these point to the benefits of having a common care labelling standard in the textile industry (Nadvi \& Wältring, 2002).

This paper seeks to reduce the complexity and confusion of care labelling systems by providing a comparative overview across a range of common standards. This is because literature review was found lacking comprehensive and detailed studies comparing different systems available in the textile industry and investigating other issues related to care label systems. This study aims at distinguishing different standards by providing (from a comparative perspective) the similarities and differences across the studied standards. The objective of this paper is to enable all parties involved in textile industry to gain an overview on standards used for care labelling, and to bring out common standard would be employed as a global standard.

It is expected that this study may draw inspiration and give insight into future research on global symbols for textile and clothing industry. The findings of this study will interest and benefit all parties concerned with care labelling standards. These are consumers, international organizations, globally operating buyers and producers, and UN agencies.

\section{Limitations of the study}

There are different care-labeling systems adopted by different countries across the world to meet national and international trade requirements. The International Trade Administration (ITA) -an American organization works on improving the global business environment- has scheduled the requirements of labeling textile goods including language, fiber content origin, necessity/optionality, size and care. ITA has referred to Intertek brochure entitled "Care label recommendations" to attain more information related to care labeling symbols (intertek). This brochure introduced the symbols and words used by some common countries namely Aus- tralia, Canada, China, European Union, Japan and USA. These countries apply compulsory standards for care guidelines into textile projects in apparel and home furnishing. It is regarded that those countries were adopted as the core marketplace where many manufacturers, importers and retailers are interested in. Therefore, this study considers that investigation on the standards of those countries may draw improvements for future system helping industry to meet the current national and international requirements.

Moreover, the draft standard newly released in 2017 of a country in Africa "Tanzania" was analyzed. As Tanzania has been considered as a potential important sourcing country for international buyers, comparison and review of its standard may offer a guideline in care label to elevate its growing commerce (Tanzania: opportunities for the textile and clothing industry, 2016). The South Korean national standard will be discussed in order to be compared with previously mentioned standard.

\section{Priority of care label system}

The importance and priority degree of care labeling systems could be mandatory, optional or desirable. Care labeling was found mandatory in Australia, China, Japan and South Korea. On the other hand, it is optional in Canada and Tanzania (International trade administration). However, the optionality of care labeling is different across European Union countries.

\section{Identification of the systems analyzed}

A system of textile care symbols is a group of pictograms divided into several subgroups illustrating and representing the maximum conditions applied to a textile article in order to maintain its appearance and properties. In the current study, the following systems/standards were analyzed.

- ISO 3758:2012 is the current standard adopted by the European countries. The British Standard BS EN ISO 3758:2012 is the UK implementation of EN ISO 3758:2012. It supersedes BS EN ISO 3758:2005, which is withdrawn (British Standards Institution, 2012). It is noteworthy that different countries have adopted an identical standard of ISO 3758:2012. This is the case in the Mexican Standard NMX-A-3758-INNTEX-2014 (SGS, 2017).

- JIS L 0001:2014 is the Japanese standard "Textiles - Care labeling code using symbols". It has a relationship with ISO 3758:2012 (MOD) as the corresponding international standard. It replaces JIS L0217-1995 (General Association of Textile Evaluation Technical Council, 2014).

- AS/NZS 1957:1998 is the code of the Australian/New Zealand standard "Textiles - Care labeling" supersedes DR 96087 and 
AS 1957-1987. It has a relationship with ISO 3758:2012 (MOD) as the corresponding international standard (Standards Australia \& Standards New Zealand, 1998).

- GB/T 8685-2008 is the adopted standard in China. It is based on ISO 3758: 2005, MOD "Textiles - Care labeling code using symbols". This standard supersedes GB/T 8685-1988 (National Standard of the People's Republic of China, 2008).

- ASTM D5489-14 is currently the active standard in the USA titled "Standard Guide for Care Symbols for Care Instructions" on Textile Products. It supersedes a series of American standards namely; D5489-07(2013)e1, D5489-07, D5489-01a, D5489-01, D5489-98a, D5489-96c (ASTM International, 2014).

- CAN/CGSB-86.1-2003 is the Canadian standard of textile care labeling titled "Care Labeling of Textiles". This standard supersedes CAN/CGSB-86.1-2003 which came after a series of standards namely 86-GP-1, 86-GP-1a, CAN2-86.1-M79,CAN/ CGSB-86.1-M87, CAN/CGSB-86.1-M91.

- TZS 692: 2003 (1st Ed) is the Tanzanian active standard. Although a draft coded with TDC4 (5029)P3 (Tanzania Bureau of Standards, 2003) titled "Textiles - Guide for care labeling on Textile products" prepared by Tanzania bureau of standard is analyzed in this study(Tanzania Bureau of Standards, 2003). This standard is proposed for adoption from July 2017 (Commission, 2017; Indian trade portal).

- KS K 0021:2011 is the South Korean current standard. It is entitled "Textiles - Care labelling code using symbols" and published by Korean Standards Association (Korean Standards \& Certifications, 2017).

\subsection{Basic common symbols}

In this section, similarities and differences between symbols used in different countries are discussed. See Fig.1 for the basic pictograms used in most care labeling systems. Additional symbols shown in Fig. 2 could be added to indicate alternative meanings.

\subsection{Regional and national requirements in care labeling}

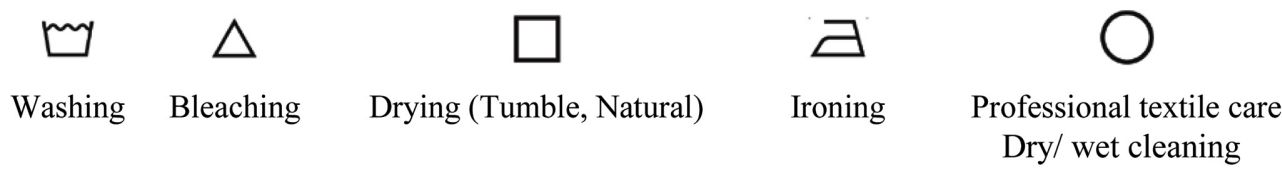

Fig. 1. The main/default five symbols used by most textiles care labeling standards (normal process).
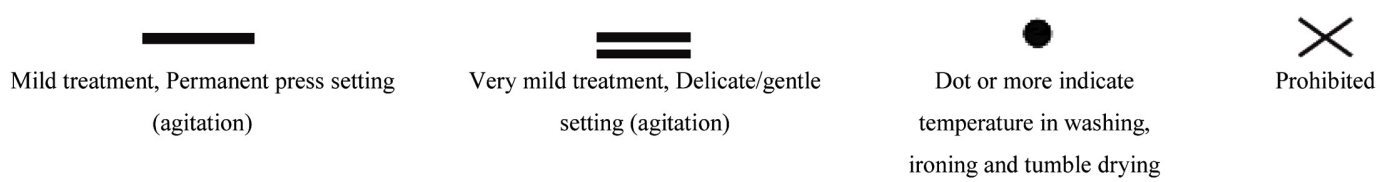

Fig. 2. Main descriptive markings, i.e. cross, bars and dots would be added to the basic symbols to further define the care procedure

\section{symbols}

In this section, symbol systems used in the standards studied will be analyzed and compared in terms of washing, bleaching, drying (tumble-natural), ironing and professional cleaning (chemical-wet). In the standards discussed a minimum of four main symbols should be used. These are washing, bleaching, drying and ironing symbols.

\subsection{Washing symbols}

Washing symbols represent two features, i.e. temperature and agitation. The temperature degrees used are 95, 70, 60, 50, 40 and $30^{\circ} \mathrm{C}$. These temperature degrees could be presented using numerical figures, dots or both. Different combinations of these two features (i.e. temperature and agitation) make up the range of symbols in each standard.

\subsubsection{Symbols of agitation degree}

Agitation is presented by the default washing tub symbol for normal cycle in all standards. One and two underlines symbolize the washing process in different standards differently. This would be due to different options of washing machines used. One underline symbolizes mild/reduced agitation in European, Chinese, Japanese and Tanzanian standards, however, symbolizes permanent press cycle in American and Canadian standards. Permanent cycle employs normal agitation cycle and slow spin of the delicate cycle so as not to wrinkle clothes. In other words, it uses a 'fast/slow' combination. Two underlines symbolize very mild/reduced agitation in European, Chinese, Japanese and Tanzanian standards, however, symbolizes delicate cycle in American and Canadian standards. Delicate/gentle cycle employs slow agitation cycle and slow spin of the delicate cycle. In other words, it uses a 'slow/slow' combination (Hill, 2010). Permanent press and gentle/delicate cycle instructions maybe reported in symbols or words. Generally, the lower temperature used in washing is, the availability of more delicate washing cycles will be. In the South Korean standard, agitation levels are but text on the symbols used. 


\subsubsection{Listing of instructions/symbols used}

All discussed standards provide the range of symbols used except the American and AS/AZ standards. The American and AS/ AZ standards provide group of symbols and words respectively presenting temperature and agitation. The manufacturers are responsible for setting up the symbols according to the proposed optimum condition of washing. In this study, all possible symbols equivalent to other standards are setup for comparison purposes.

\subsubsection{Kind of washing machine used}

In American and Canadian standards, all washing cycles (temperatures and agitations combinations) are done using domestic or commercial washing machines except the one at $95^{\circ} \mathrm{C}$. It is done using commercial washing machine. In European, Chinese, Japanese, Tanzanian and South Korean standards, the usage of domestic or commercial washing machines are not stated.

\subsubsection{Options of symbols used}

In the European, Chinese, Japanese, Australian, Tanzanian and South Korean standards there is one option in terms of the group of symbols used. European, Chinese and Japanese standards are identical with regards to range of washing symbols used.
These systems are based on figures.

This is not the case in both American and Canadian standards. There are options in both of them representing washing instructions (i.e. three options for the first and two options for the latter). In the Canadian standard using dots is a must. However, adding figures to the dots is an option. The American standard has three groups / options of washing symbols (i.e. dots, figures and dots, only figures). Therefore, both American and Canadian standards have dots and (figures and dots) symbol groups, but the American standard has only figures group which is similar to the European ones.

\subsubsection{Range of symbols used}

From Table 1, it is evident that the combinations of symbols used in European, Chinese and Japanese standards represent the following: $95,70^{\circ} \mathrm{C}$ (normal process/ one level of agitation), $60,50^{\circ} \mathrm{C}$ (normal or mild process / two levels of agitation), $40,30^{\circ} \mathrm{C}$ (normal, mild or very mild/ two levels of agitation) processes. This shows a clear reverse relationship between temperature and variety of agitation degrees used. The Tanzanian standard employs similar symbols to these standards; however, it uses fewer options of temperature and agitation degrees, i.e. 95 and $30^{\circ} \mathrm{C}$ (normal cycle), $40^{\circ} \mathrm{C}$ (mild or very mild cycles). This standard has the least number

Table 1. Washing symbols used in the standards adopted by Australia, Canada, China, Europe, Japan, USA, Tanzania and Korea

\begin{tabular}{|c|c|c|c|c|c|c|c|c|c|c|c|}
\hline Country & Australia & \multicolumn{2}{|c|}{ Canada } & China & Europe & Japan & & USA & & Tanzania & South Korea \\
\hline $\begin{array}{l}\text { Maximum temp } 95^{\circ} \mathrm{c} \\
\text { Normal process }\end{array}$ & $\begin{array}{c}\text { Boil } \\
\text { Machine wash }\end{array}$ & 屩 & :8: & 95 & ra & 95 & 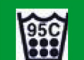 & $8: 9$ & 950 & 95 & \begin{tabular}{|l|}
$\mathrm{O}$ \\
$95^{\circ} \mathrm{C}$
\end{tabular} \\
\hline Maximum temp $95^{\circ} \mathrm{cpermanent} \mathrm{press/mild}$ & $\begin{array}{c}\text { Boil } \\
\text { Gentle machine wash }\end{array}$ & 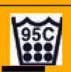 & : & & & & $\mid \widetilde{950}$ & :a: & $\tilde{55}$ & & \\
\hline Maximum temp $95^{\circ} \mathrm{c}$-Delicate/very mild & & & & & & & asc & $\because$ & ש & & \\
\hline $\begin{array}{l}\text { Maximum temp } 70^{\circ} \mathrm{c} \\
\text { Normal process }\end{array}$ & Very hot machine wash & :06 & $\ddot{009}$ & 70 & 70 & 70 & 鹿 & \% & 70 & & \\
\hline Maximum temp $70^{\circ} \mathrm{c}$-permanent press/mild & $\begin{array}{l}\text { Very hot gentle machine } \\
\text { wash }\end{array}$ & & & & & & 藏 & & $0 /$ & & \\
\hline Maximum temp $70^{\circ} \mathrm{c}$ Delicate/very mild & & & & & & & 藏 & & t] & & \\
\hline $\begin{array}{l}\text { Maximum temp } 60^{\circ} \mathrm{c} \\
\text { Normal process }\end{array}$ & $\begin{array}{l}\text { Hot machine wash } \\
60\end{array}$ & 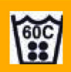 & $\because: 1$ & 600 & 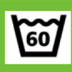 & $\sqrt{60}$ & $\mid \widetilde{6} 6$ & :8: & 1) & & \begin{tabular}{|l|}
0 \\
$60^{\circ} \mathrm{C}$ \\
\end{tabular} \\
\hline $\begin{array}{l}\text { Maximum temp } 60^{\circ} \mathrm{c} \\
\text { Permanent press/Mild }\end{array}$ & Hot gentle machine wash & {$\left[\begin{array}{c}600 \\
80\end{array}\right]$} & $8:$ & $y$ & r60 & rot & $\mid \widehat{60 c}$ & $:: 7$ & & & \\
\hline Maximum temp $60^{\circ} \mathrm{c}$-Delicate/very mild & & & & & & & $\mid \widetilde{60}$ & 8 & 60 & & \\
\hline $\begin{array}{l}\text { Maximum temp } 50^{\circ} \mathrm{c} \\
\text { Normal process }\end{array}$ & & 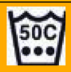 & 0.0 & roy & Foy & roy & $\widehat{50 \mathrm{C}}$ & & 50 & & \\
\hline $\begin{array}{l}\text { Maximum temp } 50^{\circ} \mathrm{c} \\
\text { Permanent press } / \text { Mild }\end{array}$ & & $50 \mathrm{C}$ & 0 & [50] & [50] & [50] & 50. & $\cdots$ & 50 & & \\
\hline $\begin{array}{l}\text { Maximum temp } 50^{\circ} \mathrm{c} \\
\text { Delicate/Very mild process }\end{array}$ & & $\mid \begin{array}{cc}500 \\
\bullet \bullet 0\end{array}$ & 0 & & & & 50. & | & $m_{5}$ & & \\
\hline
\end{tabular}


Table 1. Washing symbols used in the standards adopted by Australia, Canada, China, Europe, Japan, USA, Tanzania and Korea (continued)

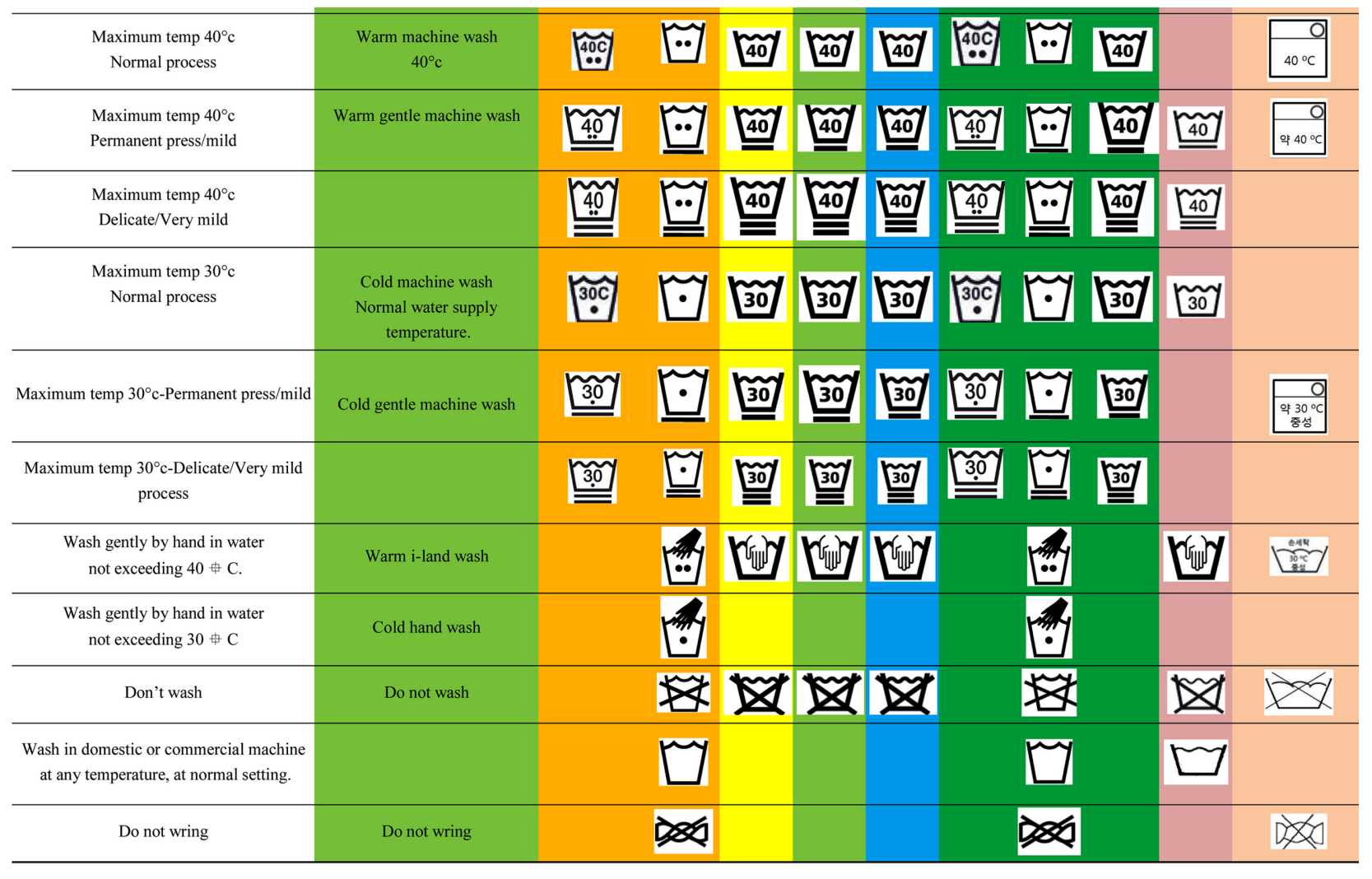

of symbols among standards discussed. The symbols used in the South Korean standard are different from other standards. It shows the washing temperature using figures. Temperatures used are as follows: 95, 60, 40 and 30. Mild agitation is recommended for low temperatures i.e. 30 and 40.

Regarding levels of agitation, the American standard has three levels of agitation for all temperatures (i.e. 95, 70, 60, 50, 40, and $30^{\circ} \mathrm{C}$ ). The Canadian standard represents three levels of agitation for temperatures $30,40,50^{\circ} \mathrm{C}$, two levels for $60,95^{\circ} \mathrm{C}$ and only normal agitation for $70^{\circ} \mathrm{C}$.

In the AS/NZ standard, two agitation levels (i.e. machine / normal and gentle machine wash) and 5 temperature degrees Celsius (i.e. cold / normal water supply, warm $/ 40^{\circ} \mathrm{C}$, hot $/ 60^{\circ} \mathrm{C}$, very hot / $70^{\circ} \mathrm{C}$, boil $/ 95^{\circ} \mathrm{C}$ ) were given. The combinations produced from these words are listed in Table 1.

\subsubsection{Prohibiting, hand washing and wringing}

All standards have similar one symbol prohibiting washing. AS/ NZ uses the phrase "Do not wash". The hand wash in European, Chinese, Japanese and Tanzanian standards are at a temperature not exceeding $40^{\circ} \mathrm{C}$. However, in AS/NZ, Canadian and American, there are two options for hand wash (i.e. 40 and $30^{\circ} \mathrm{C}$ ). Both Cana- dian and American standards use the default washing tub symbol for machine at any temperature using normal cycle and a symbol prohibiting wringing. The South Korean standard is significant for listing a symbol allowing wringing for short time.

\subsubsection{Bleaching}

In all standards discussed except the South Korean standard, there are three bleaching symbols based on the main triangle shape of bleaching (see Fig. 1). These three symbols are listed in Table 2. A blank triangle is for any bleaching agent if needed, a triangle with two lines inside is for oxygen/ non-chlorine bleach, prohibiting bleaching is represented by a crossed triangle either blank or filled with black. As mentioned above, Australian/New Zealand standard employs phrases rather than symbols for bleaching instructions. There were different phrases found representing usages of bleaching agents such as "non-chlorine bleach" and "don't bleach". It is noteworthy that the South Korean standard is based on the main symbol used for bleaching i.e. triangle. However, this standard has substituted descriptive markings used in other standards with text. Moreover, the South Korean Standard has a wider range of symbols i.e. six symbols rather than the three used in all other standards. These symbols are as follows: use chlo- 
Table 2. Bleaching symbols used in the standards adopted by Australia, Canada, China, Europe, Japan, USA, Tanzania and Korea

\begin{tabular}{|c|c|c|c|c|c|c|c|c|}
\hline & Australia & Canada & China & Europe & Japan & USA & Tanzania & South Korea \\
\hline $\begin{array}{c}\text { Any bleaching agent } \\
\text { allowed }\end{array}$ & & & & & & & & \\
\hline $\begin{array}{l}\text { Only oxygen /non } \\
\text { chlorine bleach } \\
\text { allowed }\end{array}$ & $\begin{array}{l}\text { ONLY NON-CHLORINE } \\
\text { BLEACH WHEN NEEDED }\end{array}$ & & & & & & & \\
\hline Do not bleach & DO NOT BLEACH & & & $\boldsymbol{A}$ & & & $\boldsymbol{A}$ & - \\
\hline
\end{tabular}

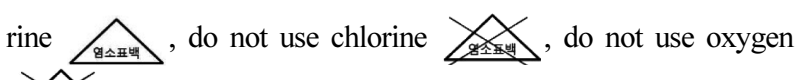
.

However, there is no equivalent phrase to the symbol allowing any bleaching agent. All standards discussed except AS/NZ have identical symbols of any bleach and bleach use oxygen only. The difference between standards is in the prohibiting crossed symbol i.e. a crossed blank triangle in standards of China, Europe, Japan and Tanzania, and a crossed triangle filled with black in standards of Canada and USA.

\subsubsection{Drying Symbol}

The drying process is carried out using two processes. These are tumble and natural drying. Both of them are represented using a square. An inside circle is used for tumble drying, and line/s could be used for natural drying.

\subsubsection{Tumble drying}

Tumble drying is defined as a process carried out on textile articles after washing and hydro-extracting, with the intention of removing residual water by treatment with hot air in a rotating drum (British Standards Institution, 2012; Standards Australia \& Standards New Zealand, 1998). Therefore, the process of tumble drying (like washing) includes agitation and temperature. All standards discussed have the symbol prohibiting tumble drying.

\subsection{Temperature of tumble drying}

European, Chinese, Japanese and Tanzanian standards are identical representing two options of tumble drying at maximum temperature degrees 80 (medium temperature) or $60^{\circ} \mathrm{C}$ (low temperature). However, in the standards of USA, Canada, AS/NZ, there are three options of temperature levels. These are high (hot in AS/NZ), medium (warm in AS/NZ), and low. Temperature is not determined in American and $\mathrm{AS} / \mathrm{NZ}$ but provided in the Canadian standard as follows: high is $75^{\circ} \mathrm{C}$, the medium is $65^{\circ} \mathrm{C}$ and low $55^{\circ} \mathrm{C}$ (see Table 3). Any heat and no heat options are presented in American and Canadian standards (see Table 3).

\subsection{Agitation in tumble drying}

Again European, Chinese, Japanese and Tanzanian standards are similar having only normal cycle for tumble drying. In AS/NZ, agitation level is not stated which means that it applies normal cycle. Although, the American standard has three levels of agitation for each temperature namely normal, permanent and gentle cycles. The American standard presents the highest variety of options for tumble drying regarding temperature used and agitation.

Tumble drying of the Canadian standard is presented by normal cycle for all temperature degrees except at $55^{\circ} \mathrm{C}$. Permanent press is presented for 55 and $65^{\circ} \mathrm{C}$ and gentle cycle for $55^{\circ} \mathrm{C}$. This shows the relation between temperature degree and agitation used. The lower tumble drying temperature will be, the lower agitation level will be employed. It is evident that the South Korean standard has two symbols for machine drying. These are for allowing or not allowing machine drying.

\subsubsection{Natural drying}

Natural drying is carried out while it is flat or hung up in light or shade. It could be done after or without hydro-extraction (called drip dry).

\subsection{Range of instructions}

It is evident from that symbols for line, flat and drip line dry in light and shade are provided by the Canadian, Chinese, European, Japanese and American standards. But, Canadian and American standards do not include drip flat dry in light or shade. However, these standards include a prohibiting tumble drying symbol. The Tanzanian and South Korean standards have two symbols representing drying in the shade or not. The South Korean standard represents these two processes using hangers i.e. $\mathrm{NZ}$ standard has a group of instructions/words available.

\subsection{Symbols and words used (similarity of shape)}

Chinese, European, Japanese are identical in terms of symbols used. Canadian and American standards have identical symbols 
Table 3. Tumble drying symbols used in the standards adopted by Australia, Canada, China, Europe, Japan, USA, Tanzania and Korea

\begin{tabular}{|c|c|c|c|c|c|c|c|c|}
\hline & Australia & Canada & China & Europe & Japan & USA & Tanzania & South Korea \\
\hline Normal cycle & $\begin{array}{l}\text { MA Y BE TUMBLE } \\
\text { DRIED-HOT }\end{array}$ & & & & & & & \\
\hline Permanent press & & & & & & & & \\
\hline Gentle cycle & & & & & & & & \\
\hline Normal process & $\begin{array}{l}\text { MA Y BE TUMBLE } \\
\text { DRIED-WARM }\end{array}$ & $\begin{array}{l}65^{\circ} \mathrm{c} \\
\text { Medium heat }\end{array}$ & $\begin{array}{l}\text { (-0) } \\
80^{\circ} \mathrm{C}\end{array}$ & $\begin{array}{l}00 \\
80^{\circ} \mathrm{C}\end{array}$ & $\begin{array}{l}00 \\
80^{\circ} \mathrm{C}\end{array}$ & Medium Heat & $\begin{array}{l}\text { (0) } \\
80^{\circ} \mathrm{C}\end{array}$ & \\
\hline Permanent press & & $65^{\circ} \mathrm{c}$ & & & & Medium Heat & & \\
\hline Gentle cycle & & & & & & $\underset{\text { Medium heat }}{200}$ & & \\
\hline Normal process & $\begin{array}{l}\text { MA Y BE TUMBLE } \\
\text { DRIED-COLD }\end{array}$ & & $\begin{array}{c}\qquad 0 \\
60{ }^{\circ} \mathrm{C} \\
\text { Low heat }\end{array}$ & $\begin{array}{c}\text { Low heat } \\
\text { Lo } \\
\text { Lo }\end{array}$ & $\begin{array}{l}\qquad 0_{6{ }^{\circ} \mathrm{C}} \\
\text { Low heat }\end{array}$ & & $\begin{array}{c}\text { Low heat } \\
\text { Lo } \\
\text { Lo }\end{array}$ & \\
\hline Permanent press & & $55^{\circ} \mathrm{C}$ & & & & & & \\
\hline Gentle cycle & & $55^{\circ} \mathrm{C}$ & & & & Low heat & & \\
\hline Any heat & & & & & & & & \\
\hline $\begin{array}{l}\text { Permanent press } \\
\text { Any heat }\end{array}$ & & & & & & & & \\
\hline $\begin{array}{l}\text { Gentle cycle } \\
\text { any heat }\end{array}$ & & & & & & & & \\
\hline No Heat & & & & & & $\Gamma$ & & \\
\hline $\begin{array}{l}\text { Permanent press } \\
\text { No heat }\end{array}$ & & & & & & $\bar{\Gamma}$ & & \\
\hline $\begin{array}{c}\text { Gentle cycle } \\
\text { No heat }\end{array}$ & & & & & & & & \\
\hline Do not tumble dry & DO NOT TUMBLE DRY & & & & 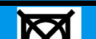 & & & \\
\hline
\end{tabular}

(different from the symbols of the previous group of standards). These standards mentioned are all having similar symbol of flat dry. The Tanzanian and South Korean standards have two symbols different from others representing light and shade natural drying. In the Japanese standard, the use of natural drying symbols is mandatory. AS/ NZ standards have phrases for alternative drying process (see Table 4).

\subsubsection{Ironing}

In all standards discussed except the South Korean one, the symbol used is hand iron with dot/s representing temperature in Celsius degrees. Three levels of maximum temperature: $200^{\circ} \mathrm{C}$ (3 dots), $150^{\circ} \mathrm{C}$ ( 2 dots $)$ and $110^{\circ} \mathrm{C}(1 \mathrm{dot})$ are used. The South Korean standard represents the three levels of temperatures using Celsius degrees and figures 1, 2 and 3. Ironing using cover signifies the South Korean standard. This is represented by the normal symbols 
Table 4. Natural drying symbols used in the standards adopted by Australia, Canada, China, Europe, Japan, USA, Tanzania and Korea

\begin{tabular}{|c|c|c|c|c|c|c|c|c|}
\hline & Australia & Canada & China & Europe & Japan & USA & Tanzania & South Korea \\
\hline Line dry & Line dry & F & & & & & Drying in the sun & Allow to dry in the sun \\
\hline Flat drying & Dry flat & & & & & & & \\
\hline Drip line drying & DRIP DRY & & & & & & & \\
\hline Drip flat drying & & & & & & & & \\
\hline Line dry in the shade & $\begin{array}{l}\text { DRY IN SHADE } \\
\text { HANG BY CORNERS AND } \\
\text { DRY IN SHADE }\end{array}$ & & & & & & $\begin{array}{l}\text { Drying in the sun } \\
\text { is not permitted }\end{array}$ & Dry in the shade \\
\hline Dry flat in shade & DR Y FLAT IN SHA DE & $\nabla$ & $F$ & $F$ & & $\mathbb{Z}$ & & \\
\hline Drip dry in shade & & & & GI & & 8 & & \\
\hline $\begin{array}{l}\text { Drip flat drying in the } \\
\text { shade }\end{array}$ & & & $=$ & $E$ & $=$ & & & \\
\hline Don't dry & & & & & & & & \\
\hline
\end{tabular}

supported by curvy line underneath each symbol of the three as follows: to represent severity of temperature used (i.e. hot, warm, cool iron, don't iron, don't steam) (see Table 5).

\subsubsection{Steam usage}

Prohibiting of steam is presented in the American, Canadian and
Australian standards. Steam is prohibited at low temperature in Chinese, European, Japanese, Australian and Tanzanian standards. However, it is done with or without steam Canadian and American standards.

4.2.5. Professional cleaning

4.2.5.1. Chemical (dry) cleaning

Table 5. Ironing symbols used in the standards adopted by Australia, Canada, China, Europe, Japan, USA, Tanzania and Korea

\begin{tabular}{|c|c|c|c|c|c|c|c|c|}
\hline & Australia & Canada & China & Europe & Japan & USA & Tanzania & South Korea \\
\hline $\begin{array}{c}\text { iron at maximum sole-plate } \\
\text { temperature of } \\
200{ }^{\circ} \mathrm{C}\end{array}$ & HOT IRON & & & & & & & 180. \\
\hline $\begin{array}{l}\text { iron at maximum sole-plate } \\
\text { temperature of } 150{ }^{\circ} \mathrm{C}\end{array}$ & WARM IRON & & & & & & & \\
\hline $\begin{array}{l}\text { iron at maximum sole-plate } \\
\text { temperature of } 110{ }^{\circ} \mathrm{C} \text { without } \\
\text { steam }\end{array}$ & $\begin{array}{l}\text { COOL IRON } \\
\text { No steam }\end{array}$ & $\begin{array}{l}\text { With or without } \\
\text { steam }\end{array}$ & without steam & without steam & without steam & $\begin{array}{l}\text { With or without } \\
\text { steam }\end{array}$ & without steam & \\
\hline Don't iron & Do not iron & $x$ & & & & & & \\
\hline Don't steam & $\begin{array}{l}\text { DO NOT STEAM } \\
\text { IRON }\end{array}$ & & & & & & & \\
\hline
\end{tabular}


Table 6. Chemical professional cleaning symbols used in the standards adopted by Australia, Canada, China, Europe, Japan, USA, Tanzania and Korea

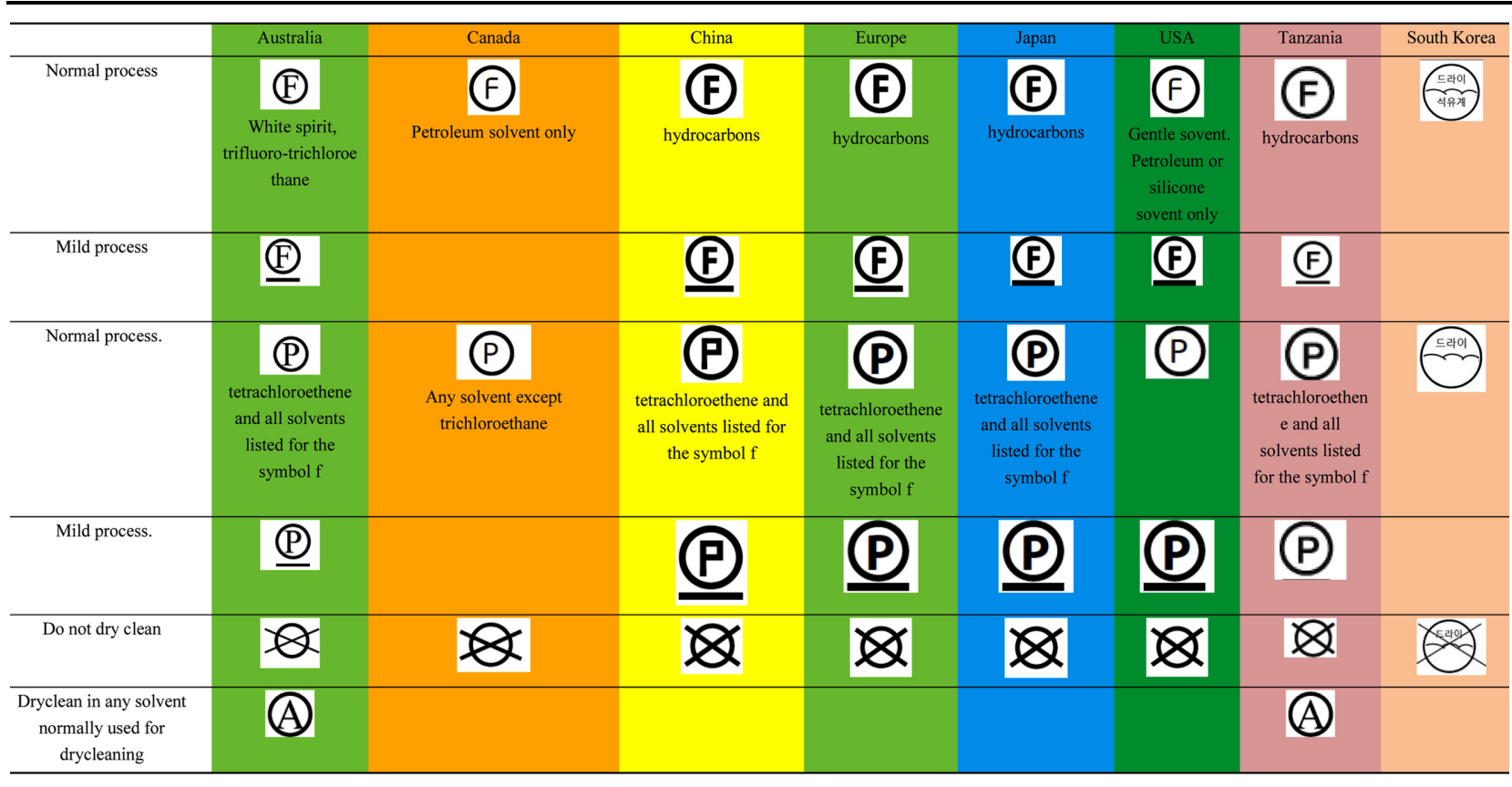

Generally, AS/NZ standard is based on phrases rather than symbols. But, in the professional chemical cleaning, symbols are employed. These symbols are similar to other standards (see Table 6).

The symbo $(P$ is used for representing drycleaning employing Tetrachloroethane and solvents stated in $(F$ (i.e. hydrocarbons).

The symbol $\odot$ symbolizes the usage of hydrocarbons in dry cleaning. AS/NZ and Tanzanian standards have a symbol presenting dry-clean in any solvent normally used for drycleaning. All standard has mild treatments except the Canadian one. It is the only standard does not have mild process in both treatments. In this process, the South Korean standard retained the default symbol namely the circle sued by other standards. It is the only standard used text instead of symbolic letters used by other standards. In this standard drycleaning is presented by two symbols for perchlorethylene or petroleum and only petroleum. This standard is significant for using a symbol representing only professional drycleaning . This symbol does not exist in other standards because it is already considered a professional process.

\subsubsection{Wet cleaning}

The symbol (W) represents professional wet cleaning. These are normal, gentle and very gentle cycles and prohibiting. American, European, Japanese and Tanzanian have the full range of symbols. Although, the American standard have different symbol prohibiting wet cleaning. The Canadian standard has two professional cleaning options to be done with normal cycle or not. The Chinese

Table 7. Professional wet cleaning symbols used in the standards adopted by Australia, Canada, China, Europe, Japan, USA, Tanzania and Korea

\begin{tabular}{lcccc}
\hline & Australia & Canada & China \\
\hline $\begin{array}{c}\text { Professional wet cleaning } \\
\text { Normal process }\end{array}$ & N/A & Europe \\
\hline Gentle wet cleaning &
\end{tabular}


standard does not present a prohibiting symbol. AS/NZ and South Korean standards do not provide professional wet cleaning.

\subsubsection{Additional wording}

In the standards discussed (except AS/NZ), words or phrases could be added to the symbols used in order to clarify, indicate or warn the consumer for doing a care activity which could harm the textile article (British Standards Institution, 2012). If this is the case, languages used should be considered. In the standard Canadian words of English and French should be used.

\section{Findings}

In this study, care labeling standards of common countries in the textile market namely Australia, Canada, China, Europe, USA and Japan were analyzed. Besides, a standard newly published for a promising market namely Tanzania was discussed. The national standard of South Korea was discussed. It is evident that all standards based on symbols except the Australian standard. This standard is based on words and phrases except for the professional care section which is based on symbols. The essentiality of care label was country dependent. Regarding symbols used, it was found that there are five kinds/types of symbols, i.e. washing, bleaching, drying (tumble and natural), ironing and professional textile care.

\subsection{Washing symbols}

Standards discussed have one option with regard to the ranges of instructions provided. However, American and Canadian standards have three and two groups respectively regarding the groups of symbols available. The most comprehensive standard found is the American standard with regarding to the range of symbols provided in each group. This standard provides basic symbols used and the manufacturer set up the symbol according to fastness tests. On the other hand, the Tanzanian standard has the least number of symbols.

Three groups of correspondent/similar standards would be set according to symbols shapes and meaning. The first includes American and Canadian standards, the second includes Chinese, European, Japanese and Tanzanian standards and the last one is for the Australian one. The South Korean standard has main/default different from all other standards based on the washtub symbol.

In all standards there are three levels of agitation used except the Australian standard. It has two levels of agitations. In the American standard provides all three levels of agitation at all temperature degrees used. In the Chinese, European and Japanese standards, there is a positive relationship between agitation strength and temperature degree used. In other words, the lower the temperature used is, the milder the agitation is applied. In the Canadian stan- dard, the relation between agitation and temperature in this standard does not conform to the relation in the above case of China, Europe and Japan. As the 95 has mild agitation while the 70 have only normal process. All standards have a similar prohibiting washing symbol. American and Canadian standards have two hand washing symbols for two different temperature degrees (i.e. 30 and 40) and prohibiting wringing. A symbol for washing at any temperature is in the American, Canadian and Tanzanian standards. The South Korean standard applies normal cycles for all temperatures except $40^{\circ} \mathrm{C}$ which applies normal and mild cycles.

\subsection{Bleaching symbols}

For bleaching treatment, similar symbols are used for any, only oxygen/ non-chlorine and prohibiting. It is evident that the symbols of bleaching used are consistent in standards discussed. However, the symbol prohibiting bleaching is a blocked triangle in American and Canadian standards. The Australian standard does not provide instructions for any bleaching agent allowed. The South Korean standard is significantly different from all other standards as it employs text rather than supplemental descriptive marks.

\subsection{Drying symbols}

For tumble drying symbols, Chinese, European, Japanese, and Tanzanian standards are identical having the same range of symbols using two temperature degrees with normal cycle. Australian standard have a range of word based instructions equivalent to the previous group of standards. American and Canadian standards employ different levels of agitation and provide options for any and no heat tumble drying. However, the American standard has wider range of symbols because of employing variable agitation levels. Symbols used in standards discussed are similar in shape. However, in some cases have different meaning (i.e. temperature degree).

Natural drying is done in light and shade. It was found that Chinese, European and Japanese standards are identical in shape meaning and range of symbols provided. The Canadian and American standards have equivalent symbols with different shapes. In these standards drip flat drying is not included. The flat drying symbol is the only symbol similar among all these standards mentioned. The Tanzanian standard does not adopt the ISO standard symbols as in other processes. In the Australian standard equivalent instructions exist in words. The South Korean standard does not clearly instruct tumble drying. However, it has symbols allowing or prohibiting machine drying.

\subsection{Ironing symbols}

All standards discussed have identical symbols for ironing. The 
Australian standard has equivalent words to the symbols used. In Chinese, European, Japanese and Tanzanian standards, it is indicated that steam is not used at the low temperature $\left(110^{\circ} \mathrm{C}\right)$. In the American and Canadian standards, prohibiting steam symbol could be added for any of the three symbols representing different temperatures. The South Korean standard uses the basic symbol of ironing with figures showing the temperature degree/severity. It is the only standard significant for representing the option of covering the article being ironed. Therefore, it has the widest range of symbols for ironing.

\subsection{Professional cleaning}

The professional cleaning includes dry and wet treatments. There are normal and mild processes. From the analysis carried out, it was found that all standards discussed would have consistent symbols shape and meaning.

\section{Conclusions}

It can be concluded that the growing international trade of textile articles is pushing the need for a universal language-independent system for care labeling. This could enhance trade of textile articles across the world and assist consumer for better understanding and caring of textile articles. The researchers decided to start up this investigation by analyzing current standards of care labeling adopted by common countries.

In this study, the American standard was found the most comprehensive system providing the widest range of instructions. Therefore, it is proposed to be the global standard used universally. However, the Tanzanian standard was found of the narrowest range of instructions. With regard to instructions' format used, it is evident that most systems are based mainly on symbols. Only Australian system is based on words and phrases rather than symbols. The systems analyzed would be grouped into three groups according to format similarity. One group includes European, Chinese, Japanese and Tanzanian standards. The second group includes the American and Canadian standards. The Australian standard is separated from the previous groups as it is the only standard based on text (except professional cleaning). Generally, the South Korean standard is different from all other standards as it is the only one employs the default symbol of processes with text rather than descriptive marks. Moreover, the South Korean standard significant default/main washing symbol which is different from other standards. It is recommended that South Korean standard needs updating to be consistent with other national and international care labelling standard. This would promote and ease trading of textile goods made in South Korea.
Comparative investigation found insignificant differences between standards regarding symbols used for bleaching, ironing and professional cleaning. For the washing symbols, it is the only process having the highest number of symbols maybe because it is the process of variable conditions more than other processes. Moreover, in this process two systems were found providing different ranges of symbols namely American (three options) and Canadian (two options) standards. For tumble and natural drying symbols, inconsistent symbol shapes were found among first and second groups of standards mentioned above. In the ironing symbols, different meanings were found for similar shapes.

These findings confirm that developing an alternative universal care label standard would be characterized by two main features namely inclusiveness and comprehensiveness. The outcomes of this study indicate that the following implications should be taken into consideration in the development and improvement processes of a global care label system.

First, universalization and provision of care label symbols need to be considered for the enhancement of text based standards or the development of understandable format across many cultures as possible. This implication is based on previous research studies. There were found two points of view. One point of view indicated the importance of using text in care labelling instructions. The highest comprehension and preference format was text only, followed by text and symbols format and only symbols format was the least. Another perspective showed the importance of presenting information employing pictogram which aid low literacy people to understand information on packaging design (Jae \& DelVecchio, 2004). However, it is evident that the current Australian standard published in 1998 (based on text). The most updated ones namely American and Japanese standards published in 2014 are based on symbols. This means that the update process should be investigated in order to develop care label symbols in proper and efficient way.

Second, some symbols appeared in similar shapes but had different meanings depending on the standard. Although, some countries share correspondent standards, the differences between systems indicate that unification of symbols and meanings may be needed to provide global consumers consistent guidance.

Third, the efficiency of a detailed standard providing and covering a wide range of instructions is an important aspect.

Fourth, the fact that not all standards offer specified symbols to guide detailed care methods such as agitation, hand wash with certain temperature and flat dry either in light and shade underlines the need for systemization and practicalization of those symbols for appropriate maintenance of the products with different properties and delicacy.

Fifth, the visibility and practicality of offering variable options/ 
symbols in one standard is an important aspect of developing universal care label system.

It is noteworthy that further research is recommended investigating the integration of standards, improvements of symbols and development of textile and apparel products which will ease their maintenance and care.

\section{References}

ASTM International. (2001). Standard guide for care symbols for care instructions on textile products. In (Vol. ASTM D5489-01a). West Conshohocken, PA: ASTM International.

ASTM International. (2014). Standard guide for care symbols for care instructions on textile products. In. West Conshohocken, PA: ASTM International.

British Standards Institution. (2012). Textiles. Care labelling code using symbols. In (Vol. BS EN ISO 3758:2012). Milton Keynes: BSI.

Calisir, F., Gumussoy, C. A., Bozdurgut, N., Topaloğlu, H., \& Bayraktaroglu, A. E. (2013, October 23-25). Comprehension of care label symbols: Effects of age, gender, and education level. Paper presented at the Proceedings of the World Congress on Engineering and Computer Science, San Francisco.

Commission, E. (2017). TDC4 (5029) P3 Textiles - Guide for care labelling on textile products (16 pages, in English). Single market and standard. Retrieved from http://storage.unitedwebnetwork.com/files/ 21/92bfa7e51bb64ed09580dab6b96fbbcf.pdf

Choo, T., \& Song, J. (2000). The actual condition of care label attached to clothing and consumers' perception. Fashion \& Textile Research Journal, 2(4), 331-338.

Davis, L. L. (1987). Consumer use of label information in ratings of clothing quality and clothing fashionability. Clothing and Textiles Research Journal, 6(1), 8-14. doi:10.1177/0887302x8700600102

Draxlerová, M., Rusko, M., \& Kuracina, M. (2015). Labelling of textile products from the perspective of quality, maintenance, safety and environment. In Research Papers Faculty of Materials Science and Technology Slovak University of Technology, 23, p. 57.

General Association of Textile Evaluation Technical Council. (2014). Textiles - Care labelling code using symbols. In: Japanese Standards Association.

Hill, L. (2010). Laundry basics: How to choose the washing cycle. Retrieved from https://www.mamaslaundrytalk.com/laundry-basicshow-to-choose-the-washing-cycle/

Indian trade portal. Tanzania- TDC4 (5029) P3 Textiles - Guide for care labelling on textile products. Indian trade portal. Retrieved from http://www.indiantradeportal.in/vs.jsp?lang $=0 \& i d=0,25,127$, 5927,6386
International trade administration. Labeling Requirements. Office of textiles and apparel (OTEXA). Retrieved from http://web.ita.doc.gov intertek. Care label recommendations. In intertek (Ed.): intertek Group plc.

Jae, H. R., \& DelVecchio, D. (2004). Decision making by low-literacy consumers in the presence of point-of-purchase information. Journal of Consumer Affairs, 38(2), 342-354. doi:10.1111/j.17456606.2004.tb00873.x

Kirsi, L., \& Grimstad, K. I. (2013). Environmental and ethical perceptions related to clothing labels among norwegian consumers. Research Journal of Textile and Apparel, 17(1), 50-58. doi:10.1108/RJTA-17-01-2013-B005

Korean Standards \& Certifications, (2017). National Standards. Korean Standards \& Cetifications. Retrieved May 22, 2018, from h t t p s://standard.go.kr/K S C I/standard Intro/ getStandardSearchView.do?menuId=919\&topMenuId=502\&uppe rMenuId $=503 \& \mathrm{ksNo}=\mathrm{KSK} 0021 \& \mathrm{tmprKsNo}=\mathrm{KSK} 0021 \&$ reform $\mathrm{No}=11$

Nadvi, K., \& Wältring, F. (2002). Making sense of global standards (INEF Report 58). Duisburg: Institut fur Entwicklung und Frieden, Gerhard-Mercator University.

National standard of the people's republic of china. (2008). Textiles Care labeling code using symbols. In (Vol. GB/T 8685-2008). Singapore.

Ruoh-Nan, Y., Jennifer, Y., \& Kittichai, W. (2008). Use of care labels: linking need for cognition with consumer confidence and perceived risk. Journal of Fashion Marketing and Management: An International Journal, 12(4), 532-544. doi:10.1108/13612020810906 173

SGS. (2017). Validity of new mexican standard for textile care labelling. Retrieved from https://www.sgs.com/en/news/2017/11/ safeguards-17017-validity-of-new-mexican-standard-for-textilecare-labelling

Shin, S. (2000). Consumers' use of care-label information in the laundering of apparel products. The Journal of The Textile Institute, 91(1), 20-28. doi:10.1080/00405000008659524

Standards Australia \& Standards NewZealand. (1998). Textiles - Care labelling. In (Vol. AS/NZS 1957:1998). Homebush: Standards Australia.

Tanzania Bureau of Standards. (2003). Textiles - Guide for care labeling of textiles for laundering and dry-cleaning. In (Vol. TZS 692: 2003 (1st Ed)): Tanzania Bureau of Standards

Tanzania: opportunities for the textile and clothing industry (2016.). Textiles Intelligence.

Workman, J. E., \& Johnson, K. K. P. (1991). Effect of care instructions on evaluations of apparel attributes. Home Economics Research Journal, 20(2), 109-118. doi:10.1177/0046777491202002

(Received 29 April 2018; 1st Revised 13 May 2018; 2nd Revised 28 May 2018; Accepted 10 June 2018) 